\title{
Programmed cell death 4 protein in esophageal cancer
}

\author{
MATTEO FASSAN ${ }^{1}$, MATTEO CAGOL ${ }^{2}$, GIANMARIA PENNELLI ${ }^{1}$, CHRISTIAN RIZZETTO $^{2}$, \\ LUCIANO GIACOMELLI ${ }^{3}$, GIORGIO BATTAGLIA ${ }^{2}$, GIOVANNI ZANINOTTO ${ }^{4}$, \\ ERMANNO ANCONA ${ }^{2,4}$, ALBERTO RUOL ${ }^{4}$ and MASSIMO RUGGE ${ }^{1,2}$ \\ ${ }^{1}$ Department of Medical Diagnostic Sciences and Special Therapies, ${ }^{2}$ Istituto Oncologico Veneto-IOV-IRCCS; \\ ${ }^{3}$ Azienda Ospedaliera di Padova, Pathology Unit; ${ }^{4}$ Department of Gastroenterological and Surgical Sciences, \\ University of Padova, Padova (PD), I-35100, Italy
}

Received December 15, 2009; Accepted February 9, 2010

DOI: $10.3892 /$ or_00000838

\begin{abstract}
Screening for genes down-regulated in esophageal cancers (Oncomine database) pinpointed programmed cell death 4 (PDCD4) as one of the most consistently involved. $P D C D 4$ is a new putative tumor suppressor gene implicated in cell transformation, tumorigenesis, and invasiveness. Based on such a biological rationale, the aim of the present study was to evaluate the prognostic value of PDCD4 in esophageal cancers. The immunohistochemical expression of PDCD4 protein was assessed in 111 consecutive esophageal cancers (63 adenocarcinomas and 48 squamous cell carcinomas) and paired non-cancerous samples. PDCD4 immunostaining was significantly lower in cancer samples than in non-cancerous mucosa $(\mathrm{p}<0.001)$. In all cases, the native esophageal epithelium consistently expressed nuclear PDCD4, which was significantly less expressed (37/111 cases) or completely lacking (31/111 cases) in the cancer samples. A significant inverse correlation emerged between nuclear PDCD4 expression and tumor stage $(\mathrm{p}=0.002)$, pT $(\mathrm{p}<0.001)$, nodal metastasis $(\mathrm{p}=0.038)$, and with both vascular $(\mathrm{p}=0.005)$ and perineural invasion $(\mathrm{p}=0.004)$. Nuclear PDCD4 expression was associated with a longer disease-free $(\mathrm{p}=0.011)$ and overall $(\mathrm{p}=0.021)$ survival. PDCD4 expression predicts the patient outcome in esophageal cancers. Additional functional studies should look into the role of PDCD4 in the multistep process of esophageal oncogenesis also inquiring on the clinical usefulness of the protein expression as prognostic marker in esophageal precancerous lesions.
\end{abstract}

\section{Introduction}

Esophageal carcinoma (EC) is a highly lethal malignancy and neither radical surgery nor multimodal therapeutic protocols

Correspondence to: Dr Massimo Rugge, Department of Medical Diagnostic Sciences and Special Therapies, Istituto Oncologico Veneto-IRCCS, Via Aristide Gabelli 61, I-35121, Padova, Italy E-mail: massimo.rugge@unipd.it

Key words: esophageal cancer, $P D C D 4$, tumor suppressor gene, immunohistochemistry significantly affect its early recurrence and mortality rate (1).

Little is known as yet about the molecular mechanisms behind esophageal oncogenesis. Expanding on such biological information might point to new prognostic markers and targeted therapies $(2,3)$.

On screening for genes differently expressed in EC (Oncomine database) (4), the programmed cell death 4 (PDCD4) gene is one of those most frequently down-regulated in esophageal epithelial malignancies. The PDCD4 protein is involved in the apoptotic machinery (5) and, by interacting with translation initiation factors eIF4A and eIF4G, it suppresses cell transformation, tumorigenesis, and invasion $(6,7)$. The molecules regulated by PDCD4 include p21 (8), Cdk4, ornithine decarboxylase (9), carbonic anhydrase II (10), and JNK/c-Jun/AP-1 $(11,12)$. It is worth adding that miR-21, a promoter of cell transformation, has recently been shown to target PDCD4 expression (13-17).

Recent studies have demonstrated that PDCD4 is downregulated in different human cancers, as well as in cancer cell lines $(9,13,14,18-26)$. Moreover, loss of PDCD4 expression (as assessed by immunohistochemistry in the nucleus and/or cytoplasm) is associated with unfavorable cancer outcome $(18,22)$. Taken together, the available information points to a role of PDCD4 as a tumor suppressor gene. No studies have addressed PDCD4 expression in large series of human esophageal cancers, and the protein's expression has not been correlated with patient survival.

This study explored PDCD4 expression in a series of 111 esophageal cancers [63 esophageal adenocarcinomas (EAC) and 48 squamous cell carcinomas (ESCC)] and their paired non-neoplastic samples; the protein's expression was correlated both with the clinico-pathological features of the cancer and with clinical outcome.

\section{Materials and methods}

cDNA microarray analysis. The Oncomine database and gene microarray analysis tool, a repository for published cDNA microarray data (http://www.oncomine.org) $(4,27)$, was queried (on 15 December 2008) for PDCD4 mRNA expression in esophageal non-neoplastic tissues and primary cancers. A statistical analysis of any differences in PDCD4 
Table I. Clinico-pathological characteristics, clinical outcome and their association with PDCD4 nuclear expression in 111 patients treated for esophageal cancer.

\begin{tabular}{|c|c|c|c|c|}
\hline & EAC & ESCC & Total & P-value \\
\hline No. of cases & 63 & 48 & 111 & NS \\
\hline Age & $\begin{array}{c}65.7 \pm 10.6 \\
\text { (range 39-86) }\end{array}$ & $\begin{array}{c}65.1 \pm 8.1 \\
(\text { range } 45-81)\end{array}$ & $\begin{array}{c}65.4 \pm 9.6 \\
\text { (range 39-86) }\end{array}$ & NS \\
\hline Sex & & & & 0.011 \\
\hline Male & 58 & 35 & 93 & \\
\hline Female & 5 & 13 & 18 & \\
\hline Tumor stage & & & & 0.002 \\
\hline SI & 14 & 9 & 23 & \\
\hline SIIA-IIB & 15 & 23 & 38 & \\
\hline SIII & 14 & 8 & 22 & \\
\hline SIV & 20 & 8 & 28 & \\
\hline Tumor grade & & & & NS \\
\hline G1-2 & 33 & 39 & 72 & \\
\hline G3-4 & 30 & 9 & 39 & \\
\hline Vascular invasion & & & & 0.005 \\
\hline Yes & 43 & 29 & 72 & \\
\hline No & 20 & 19 & 39 & \\
\hline Perineural invasion & & & & 0.003 \\
\hline Yes & 16 & 21 & 37 & \\
\hline No & 47 & 27 & 74 & \\
\hline Tumor recurrence & & & & 0.011 \\
\hline No & 44 & 33 & 77 & \\
\hline Yes & 11 & 8 & 19 & \\
\hline Patient survival & & & & 0.021 \\
\hline Alive & 44 & 29 & 73 & \\
\hline Deceased & 11 & 12 & 23 & \\
\hline
\end{tabular}

NS, not significant.

expression was accomplished using the Oncomine algorithms, which enable multiple comparisons between different studies $(4,27)$. Only studies with results achieving a $p<0.05$ were considered.

Patients. One hundred and eleven esophageal cancer patients (48 ESCC and 63 EAC) who had undergone radical esophagectomy (R0) between 2002 and 2006 at the Clinica Chirurgica III-University of Padova were considered. Patients who had neo-adjuvant therapy or who died within 2 months of their operation were excluded. After surgery, 96 (41 ESCC and 55 EAC) of the 111 patients were followed up for at least 6 months or until they died (mean follow-up $22.3 \pm 14.4$ months; median 18.0; range 6.0-59.8). Tumor recurred in 19 patients, and 17 of them died of disease (the median time from recurrence to death was 4.6 months); 6 other patients died of unrelated causes (Table I; Fig. 3).
All the patients considered in this study gave their written informed consent.

Pathological study. The gross surgical specimens were all examined according to a standardized protocol. Gross serial sections were obtained from the whole resected esophagus, enabling tissue samples to be collected from both cancer and native esophageal mucosa. The tissue samples were routinely processed for histological examination; serial sections (4-6 $\mu \mathrm{m}$ thick) were obtained from paraffin blocks and stained with hematoxylin and eosin (H\&E) or used for immunophenotyping. The pTNM stage was assessed according to current criteria (28). The clinico-pathological characteristics of the series are described in Table I.

Immunohistochemical (IHC) study. In all cases, immunohistochemical staining was performed automatically (Ventana 
A

\begin{tabular}{|c|c|c|}
\hline $\begin{array}{l}\text { Gene } \\
\text { Symbol }\end{array}$ & $\begin{array}{l}\text { Gene } \\
\text { Name }\end{array}$ & P-value \\
\hline PTN & pleiotrophin & $4.01 E-4$ \\
\hline WNK1 & WNKlysine deficient protein kinase 1 & $4.81 \mathrm{E}-4$ \\
\hline $\mathrm{PDCD} 4$ & programmed cell death 4 & $7.12 \mathrm{E}-4$ \\
\hline BLVRA & biliverdin reductase $A$ & $7.23 E-4$ \\
\hline TRIM 13 & tripartite motif-containing 13 & $8.15 E-4$ \\
\hline NDRG2 & NDRG family member 2 & $8.26 \mathrm{E}-4$ \\
\hline RND3 & Rho family GTPase 3 & 0.001 \\
\hline TSPAN5 & tetraspanin 5 & 0.001 \\
\hline $\operatorname{CDg}$ & CD9 molecule & 0.001 \\
\hline CYP4B1 & $\begin{array}{l}\text { cytochrome } P 450 \text {, family } 4 \text {, subfamily } B \text {, } \\
\text { polypeptide } 1\end{array}$ & 0.001 \\
\hline
\end{tabular}

B

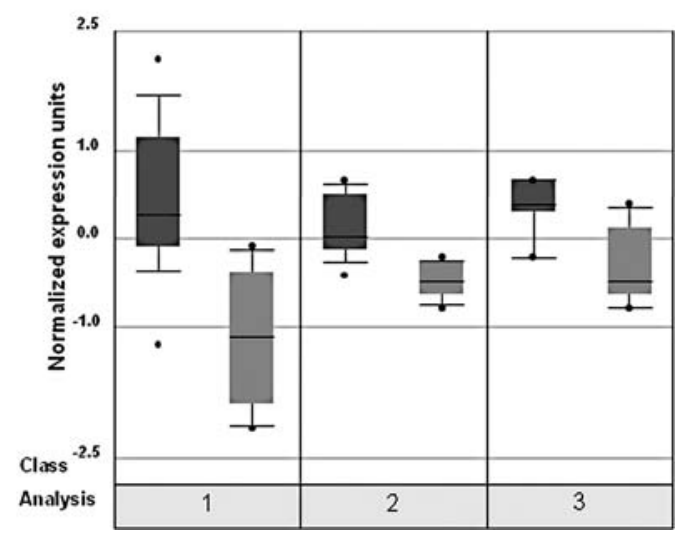

Figure 1. Oncomine analysis. Expression array analyses of multiple available esophageal cancer microarray data sets were collected and analyzed for downregulated genes, and statistical significance was calculated using the Oncomine database and gene microarray data analysis tool. (A) $P D C D 4$ was identified as the third most down-regulated gene in cancer among the three available esophageal adenocarcinoma data sets (29-31). (B) PDCD4 mRNA expression in publicly-available esophageal cancer microarray studies, showing PDCD4 expression in normal tissues (dark grey) and esophageal adenocarcinomas (light grey). Class analysis 1, Wang_Esophagus (t-test=5.294; p=6.9E-5; 24 normal, 9 EAC) (30); class analysis 2, Hao_Esophagus (t-test=5.522; p=1.2E-4; 15 normal, 5 EAC) (31); class analysis 3, Kimchi_Esophagus (t-test=3.985; p=0.001; 8 normal, 8 EAC) (29).

Benchmark XT system, Touchstone, AZ) for PDCD4 (catalog \#HPA001032; Atlas Antibodies, Stockholm, Sweden; 1:100) according to the manufacturer's instructions. Sections were lightly counterstained with hematoxylin. Appropriate positive and negative controls were run concurrently.

Criteria for assessing the immunohistochemical results. PDCD4 expression was jointly scored by two pathologists (M.F. and G.P.) with no knowledge of the clinical history of the patients. Ten high power fields (x400) were randomly selected, all of them representative of cancer tissue. Both nuclear and cytoplasmic PDCD4 immunostains were considered initially. Since only nuclear PDCD4 downregulation has been found consistently associated with (unfavorable) cancer outcome (18), nuclear PDCD4 immunoreaction was considered for the purposes of this study and cases were dichotomized as PDCD4-positive (positive staining of at least $5 \%$ of the tumor cells' nuclei) vs. PDCD4-negative (no immunoreaction). In the cancer samples, the presence of positive stromal and inflammatory cells served as an internal control. All discrepancies in scoring were reviewed and a consensus was reached.

Statistical analysis. Univariate analysis was performed on each variable. The Mann-Whitney, Fisher's exact and Pearson's correlation tests were used to analyze the differences and correlations. For the purposes of this study, the outcomes considered were the disease-free interval (defined as the months elapsing between surgery and first tumor recurrence), and overall survival (defined as the time from surgery to the patient's death). Kaplan-Meier product limit curves were also calculated. Patients with no recurrent disease were censored at the time of their last follow-up or death (due to causes unrelated to their esophageal cancer). Diseasefree and overall disease-free survival rates were compared across the levels of prognostic factors using the log-rank test. $\mathrm{P}$-values $<0.05$ were considered significant. All the statistical assessments were performed with STATA software (Stata Corporation, College Station, TX, USA).

\section{Results}

PDCD4 is one of the most down-regulated genes in publiclyavailable EC mRNA microarray studies. In screening for genes specifically down-regulated in EC, a gene expression analysis was performed by checking different publiclyavailable EC microarray studies using the Oncomine database and gene microarray data analysis tools $(4,27)$. The analysis took into account the mRNA expression levels for each of the studies; the significance of the gene expression across the available studies was also taken into account. In the three independent data sets of human esophageal adenocarcinomas considered, PDCD4 was consistently one of the most downregulated genes: PDCD4 mRNA expression levels were significantly lower in primary EC tissues than in non-neoplastic controls (Pearson's correlation, $p=7.12 \mathrm{E}-4)(29-31)$ (Fig. 1).

PDCD4 expression is down-regulated in EC. In all the normal esophageal tissue samples, the basal squamous epithelial layer (proliferative zone) featured strong PDCD4 nuclear expression (mostly coexisting with weak-moderate cytoplasm staining) (Fig. 2). PDCD4 nuclear expression was always a feature of non-epithelial cells (fibroblasts, lymphocytes, smooth muscle cells, and endothelia) in both normal and cancer samples (positive internal control) $(8,18,32)$.

Among the cancer samples, only $37 / 111$ showed any PDCD4 nuclear expression (Mann-Whitney, $\mathrm{p}<0.001$ ), and no PDCD4 immunoreaction (at nuclear or cytoplasmic level) was seen in 31 cases (Fig. 2).

No significant differences were observed in the protein's expression according to the cancer histotype (ESCC vs. EAC).

Prognostic value of PDCD4 expression. An inverse correlation emerged between PDCD4 nuclear expression and female gender (Fisher, $\mathrm{p}=0.011)$, pT (Mann-Whitney, $\mathrm{p}<0.001)$, lymph node metastasis (Fisher, $\mathrm{p}=0.038$ ), pathological tumor 

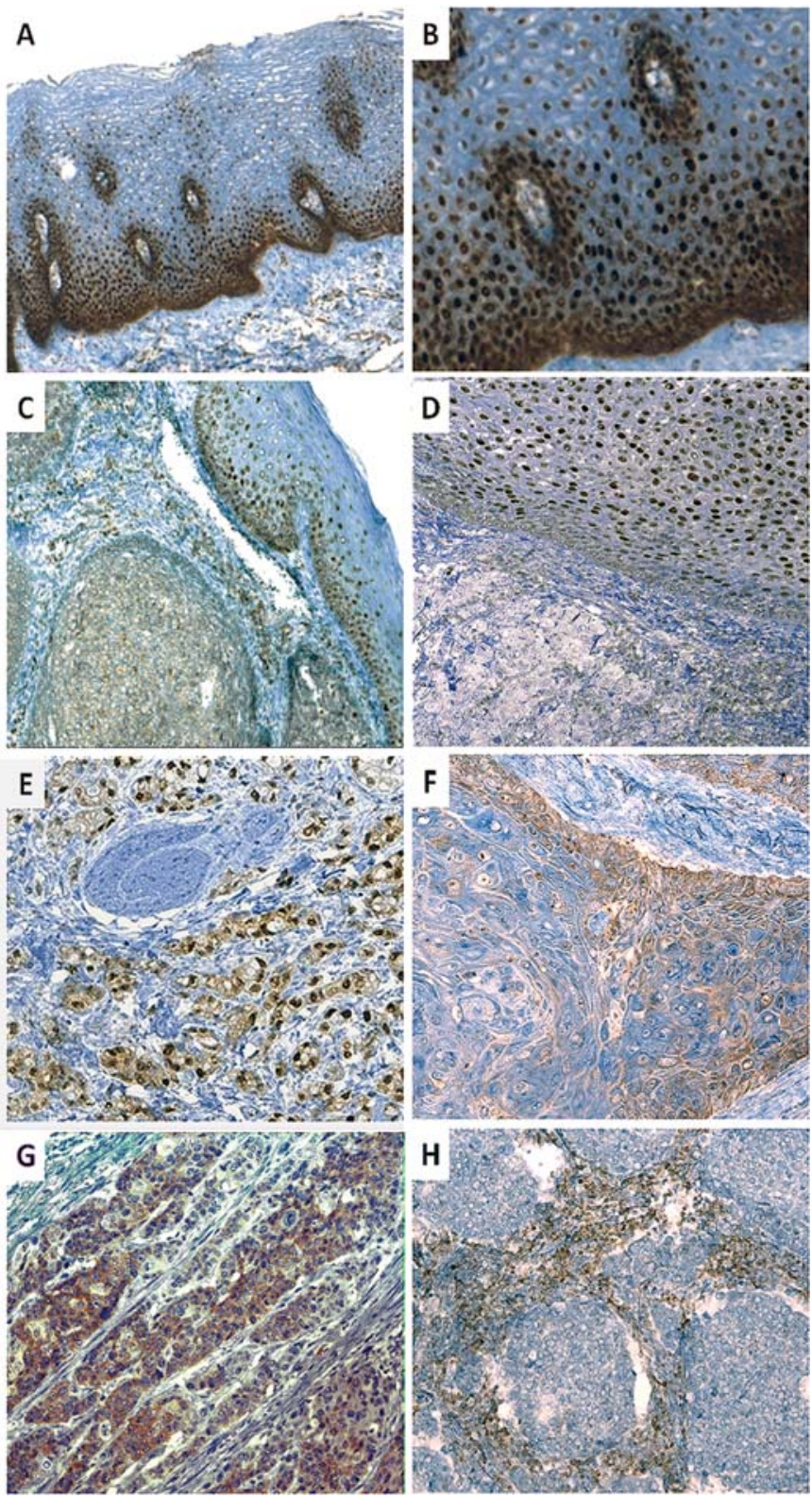

Figure 2. Representative PDCD4 immunostaining of non-cancerous and cancer tissue samples. PDCD4 immunostaining of native squamous esophageal epithelium (A and B) and squamous epithelium next to tumor cells (C and D). Normal esophageal basal cells feature strong nuclear and weakmoderate cytoplasmic staining; cancer tissue shows weak (C) or no (D) protein expression. Strong nuclear and weak-moderate cytoplasmic immunostaining of an EAC (E). Weak cytoplasmic immunostaining of an ESCC (F) and an EAC (G). A Pdcd4-negative ESCC surrounded by a nuclear-positive lymphocytic infiltrate $(\mathrm{H})$. (Original magnification, 20 and $\mathrm{x} 40$ ).

stage (Mann-Whitney, $\mathrm{p}=0.002$ ), and both vascular (Fisher, $\mathrm{p}=0.005$ ) and perineural cancer invasion (Fisher, $\mathrm{p}=0.003$ ) (Table I). PDCD4 nuclear expression was associated to both longer disease-free and overall survival (log-rank test, $\mathrm{p}=0.011$ and 0.021 , respectively; Fig. 3 ).

\section{Discussion}

Lower PDCD4 expression (both total and nuclear) has been detected in several human malignancies $(18,19,25,26)$ and PDCD4 has been shown to inhibit neoplastic transformation
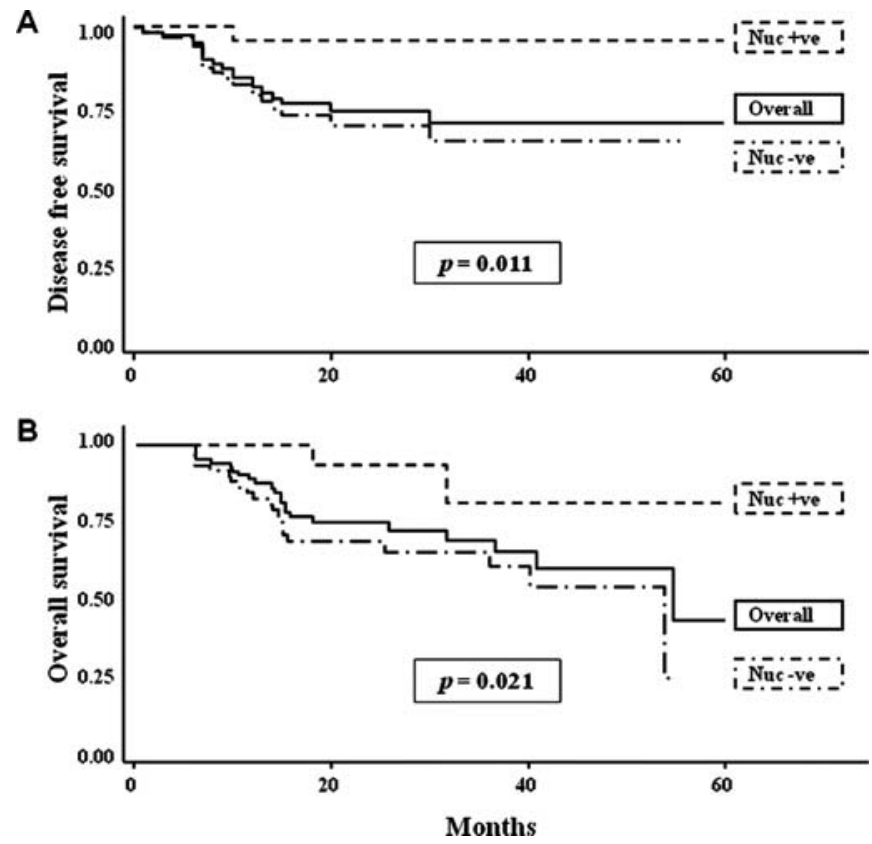

Figure 3. Disease-free (A) and overall survival (B) analyzed by KaplanMeier curves in 96 patients with radically treated esophageal carcinomas and stratified by PDCD4 immunohistochemical nuclear positivity.

in both cancer cell lines $(33,34)$ and in vivo models (i.e. skin carcinoma in transgenic mice) (9).

The available cDNA microarray databases consistently identify PDCD4 as one of the genes most frequently downregulated in EC. Hiyoshi and colleagues (17) recently found PDCD4 gene expression (RT-PCR, Western blot analysis) regulated by miR-21 in a series of ESCC, but no previous study has extensively investigated PDCD4 expression in large series of ECs.

This study considered the immunohistochemical PDCD4 expression in a cohort of consecutive esophageal cancers (both ESCC and EAC). PDCD4 protein was completely lost or significantly reduced in almost $60 \%$ of the tumor samples considered. No differences were found in PDCD4 expression in the two main histotypes of esophageal cancer (EAC vs. ESCC). Notably, similar non-histotype-specific patterns were achieved on testing the protein's expression in different lung cancer histotypes (26). These findings would suggest that $P D C D 4$ is associated with a major tumor suppressor function that would be lost early in different carcinogenesis pathways.

The prognostic value of PDCD4 down-regulation was consistently supported by its association with the most common clinico-pathological variables associated to cancer aggressiveness (i.e., tumor p-stage, pT, presence of nodal metastasis, vascular and perineural invasion). Additionally, a significant correlation was demonstrated with both overall and disease-free survival. The achieved results support the hypotheses that PDCD4 acts as a tumor suppressor and that (irrespective of the cancer histotype) it discriminates between prognostically different tumors (18).

Inconsistent information is available about the different biological meaning of the protein subcellular expression (i.e. cytoplasmic vs. nuclear). In this study, according to previous experiences, only unequivocal nuclear expression 
was considered. Various hypotheses have been advanced to explain the molecular mechanisms underlying nuclear or cytoplasmic PDCD4 expression. Under normal growth conditions, in vitro studies have demonstrated that PDCD4 is located mainly in the nucleus (35). So the significant loss of nuclear PDCD4 expression in cancer may theoretically be the result of epigenetic and/or genetic PDCD4 gene deregulation.

In conclusion, the loss of PDCD4 expression in the two main types of EC strongly supports the putative role of $P D C D 4$ in the multistep process of esophageal oncogenesis and is consistent with pivotal in silico studies which proved an elective involvement of PDCD4 in esophageal carcinogenesis. Further efforts are needed to validate the prognostic impact of PDCD4 IHC expression. Restoring PDCD4 (and its downstream signaling pathways) may potentially pave the way to the development of novel therapeutic strategies.

\section{Acknowledgements}

The authors are grateful to Valentina Zoccoletto, Vanni Lazzarin and Cristiano Lanza for their technical assistance. This study was partially supported by a 'G. Berlucchi' Foundation grant.

\section{References}

1. Jemal A, Siegel R, Ward E, Hao Y, Xu J and Thun MJ: Cancer statistics, 2009. CA Cancer J Clin 59: 225-249, 2009.

2. Enzinger PC and Mayer RJ: Esophageal cancer. NEJM 349: 2241-2252, 2003

3. Paulson TG and Reid BJ: Focus on Barrett's esophagus and esophageal adenocarcinoma. Cancer Cell 6: 11-16, 2004.

4. Rhodes DR, Yu J, Shanker K, et al: ONCOMINE: a cancer microarray database and integrated data-mining platform. Neoplasia 6: $1-6,2004$

5. Shibahara K, Asano M, Ishida Y, et al: Isolation of a novel mouse gene MA-3 that is induced upon programmed cell death. Gene 166: 297-301, 1995.

6. Yang HS, Cho MH, Zakowicz H, et al: A novel function of the MA-3 domains in transformation and translation suppressor Pdcd4 is essential for its binding to eukaryotic translation initiation factor 4A. Mol Cell Biol 24: 3894-3906, 2004.

7. Zakowicz H, Yang HS, Stark C, et al: Mutational analysis of the DEAD-box RNA helicase eIF4AII characterizes its interaction with transformation suppressor Pdcd4 and eIF4GI. RNA 11: 261-274, 2005

8. Goke R, Barth P, Schmidt A, et al: Programmed cell death protein 4 suppresses CDK1/cdc2 via induction of $\mathrm{p} 21$ (Waf1/ Cip1). Am J Physiol Cell Physiol 287: C1541-C1546, 2004.

9. Jansen AP, Camalier CE and Colburn NH: Epidermal expression of the translation inhibitor programmed cell death 4 suppresses tumorigenesis. Cancer Res 65: 6034-6041, 2005.

10. Lankat-Buttgereit B, Gregel C, Knolle A, et al: Pdcd4 inhibits growth of tumor cells by suppression of carbonic anhydrase type II. Mol Cell Endocrinol 214: 149-153, 2004.

11. Bitomsky N, Bohm M and Klempnauer KH: Transformation suppressor protein Pdcd4 interferes with JNK-mediated phosphorylation of c-Jun and recruitment of the coactivator p300 by c-Jun. Oncogene 23: 7484-7493, 2004.

12. Yang HS, Matthews CP, Clair T, et al: Tumorigenesis suppressor Pdcd4 down-regulates mitogen-activated protein kinase kinase kinase kinase 1 expression to suppress colon carcinoma cell invasion. Mol Cell Biol 26: 1297-1306, 2006.

13. Asangani IA, Rasheed SA, Nikolova DA, et al: MicroRNA-21 (miR-21) post-transcriptionally downregulates tumor suppressor Pdcd4 and stimulates invasion, intravasation and metastasis in colorectal cancer. Oncogene 27: 2128-2136, 2008.

14. Frankel LB, Christoffersen NR, Jacobsen A, et al: Programmed cell death 4 (PDCD4) is an important functional target of the microRNA miR-21 in breast cancer cells. J Biol Chem 283: $1026-1033,2008$
15. Lu Z, Liu M, Stribinskis V, et al: MicroRNA-21 promotes cell transformation by targeting the programmed cell death 4 gene. Oncogene 27: 4373-4379, 2008.

16. Talotta F, Cimmino A, Matarazzo MR, et al: An autoregulatory loop mediated by miR-21 and PDCD4 controls the AP-1 activity in RAS transformation. Oncogene 28: 73-84, 2009.

17. Hiyoshi Y, Kamohara H, Karashima R, et al: Micro-RNA-21 regulates the proliferation and invasion in esophageal squamous cell carcinoma. Clin Cancer Res 15: 1915-1922, 2009.

18. Mudduluru G, Medved F, Grobholz R, et al: Loss of programmed cell death 4 expression marks adenoma-carcinoma transition, correlates inversely with phosphorylated protein kinase B, and is an independent prognostic factor in resected colorectal cancer. Cancer 110: 1697-1707, 2007.

19. Gao F, Wang X, Zhu F, et al: PDCD4 gene silencing in gliomas is associated with $5^{\prime} \mathrm{CpG}$ island methylation and unfavorable prognosis. J Cell Mol Med (In press).

20. Jansen AP, Camalier CE, Stark C and Colburn NH: Characterization of programmed cell death 4 in multiple human cancers reveals a novel enhancer of drug sensitivity. Mol Cancer Ther 3: 103-110, 2004

21. Kalinichenko SV, Kopantzev EP, Korobko EV, et al: Pdcd4 protein and mRNA level alterations do not correlate in human lung tumors. Lung Cancer 62: 173-180, 2008.

22. Wang Q, Sun Z and Yang HS: Downregulation of tumor suppressor Pdcd 4 promotes invasion and activates both betacatenin/Tcf and AP-1-dependent transcription in colon carcinoma cells. Oncogene 27: 1527-1535, 2008.

23. Wen YH, Shi X, Chiriboga L, et al: Alterations in the expression of PDCD4 in ductal carcinoma of the breast. Oncol Rep 18: 1387-1393, 2007

24. Zhang H, Ozaki I, Mizuta T, et al: Involvement of programmed cell death 4 in transforming growth factor-beta1-induced apoptosis in human hepatocellular carcinoma. Oncogene 25: 6101-6112, 2006

25. Matsuhashi S, Narisawa Y, Ozaki I and Mizuta T: Expression patterns of programmed cell death 4 protein in normal human skin and some representative skin lesions. Exp Dermatol 16: 179-184, 2007.

26. Chen Y, Knosel T, Kristiansen G, et al: Loss of PDCD4 expression in human lung cancer correlates with tumour progression and prognosis. J Pathol 200: 640-646, 2003.

27. Rhodes DR, Yu J, Shanker K, et al: Large-scale metaanalysis of cancer microarray data identifies common transcriptional profiles of neoplastic transformation and progression. Proc Natl Acad Sci USA 101: 9309-9314, 2004.

28. Hamilton SR and Aaltonen LA: World Health Organization Classification of Tumours. Pathology and Genetics of Tumours of the Digestive System. IARC Press, Lyon, 2000.

29. Kimchi ET, Posner MC, Park JO, et al: Progression of Barrett's metaplasia to adenocarcinoma is associated with the suppression of the transcriptional programs of epidermal differentation. Cancer Res 65: 3146-3154, 2005.

30. Wang S, Zhan M, Yin J, et al: Transcriptional profiling suggests that Barrett's metaplasia is an early intermediate stage in esophageal adenocarcinogenesis. Oncogene 25: 3346-3356, 2006.

31. Hao Y, Triadafilopoulos G, Sahbaie P, Young HS, Omary MB and Lowe AW: Gene expression profiling reveals stromal genes expressed in common between Barrett's esophagus and adenocarcinoma. Gastroenterology 131: 925-933, 2006.

32. Yoshinaga H, Matsuhashi S, Fujiyama C and Masaki Z: Novel human PDCD4 (H731) gene expressed in proliferative cells is expressed in the small duct epithelial cells of the breast as revealed by an anti-H731 antibody. Pathol Int 49: 1067-1077, 1999.

33. Nieves-Alicea R, Colburn NH, Simeone AM and Tari AM: Programmed cell death 4 inhibits breast cancer cell invasion by increasing tissue inhibitor of metalloproteinases-2 expression. Breast Cancer Res Treat 114: 203-209, 2009.

34. Yang HS, Knies JL, Stark C and Colburn NH: Pdcd4 suppresses tumor phenotype in JB6 cells by inhibiting AP-1 transactivation. Oncogene 22: 3712-3720, 2003.

35. Bohm M, Sawicka K, Siebrasse JP, et al: The transformation suppressor protein Pdcd4 shuttles between nucleus and cytoplasm and binds RNA. Oncogene 22: 4905-4910, 2003. 